\title{
COVID-19: counter-intuitive data on smoking prevalence and therapeutic implications for nicotine
}

\author{
Riccardo Polosa ${ }^{1,2}$ (G) Grazia Caci ${ }^{3}$
}

Received: 25 April 2020 / Accepted: 28 April 2020 / Published online: 19 May 2020

(c) Società Italiana di Medicina Interna (SIMI) 2020

All the world is aware of the Coronavirus pandemic, and as of the 23rd of April 2020 globally 2.629.801 cases had been confirmed, and 183.454 fatalities had occurred (https://coron avirus.jhu.edu/map.html). The world is struggling and working to contain the disease and death of this active new virus. On top of the medical toll, the COVID-19 pandemic has resulted in severe economic devastation that has tragic and widespread consequences for human health and suffering.

Multiple strategies are necessary to end this pandemic. Some of these actions are supplying all health professionals with personal protective equipment, reorganizing healthcare systems with COVID-19 dedicated high-dependency hospitals/wards, testing new treatments and vaccines, and motivating people to maintain social distancing practices even when the pandemic recedes.

In the absence of long-term immunization against SARSCoV-2 or effective therapies for COVID-19, healthcare professionals must have access to clear information that accurately predicts which patients with the virus would go on to develop clinical deterioration of COVID-19 (high-risk populations). A better clinical definition of those at highrisk for severe illness with COVID-19 is vital for effective clinical assessment, risk stratification, resource allocation repositioning, and targeted public health interventions.

Some conclusive predictors of the risks for severe illness have been clearly described: the presence of co-morbidities [1], older age [2], breathlessness [3] and lymphopenia [4]. Many other predictors of COVID-19 that result in clinical severity have been proposed, but their validity has been

Riccardo Polosa

polosa@unict.it

1 Dipartimento di Medicina Clinica e Sperimentale (MEDCLIN), University of Catania, Catania, Italy

2 Center of Excellence for the Acceleration of HArm Reduction (CoEHAR), University of Catania, Catania, Italy

3 Internal Medicine, Luzerner Kantonsspital, LUKS, Luzern, Switzerland questioned. The difficulty in identifying predictors is not surprising considering that anamnestic and behavioral data might have been collected inaccurately due to the extremely challenging situations at wards/ICUs with work overloads and operating in a persistent state of emergency.

Intuitively, one vulnerability to severe illness from COVID-19 would be assumed to be cigarette smoking [8] because it is known to increase the risk of serious respiratory infections [5-7]. But is this in fact true? In this issue of Internal and Emergency Medicine, Farsalinos et al. [9] explore the hypothesis that smokers are at higher risk and unexpectedly found data that point to the opposite and counter-intuitive conclusion that smoking may actually have a protective effect. Their systematic review observed that smoking is vastly protective for hospitalized COVID19 based on the surprisingly low prevalence of smoking in patients hospitalized with COVID-19. While it is possible that the prevalence of smokers in Chinese case series may be underrepresented due to inaccurate recording of their smoking status, similar findings have been now being reported in the US, Germany and in France. The Centers for Disease Control and Prevention (CDC) [10] report an unusually low prevalence of current smoking among COVID-19 cases at $1.3 \%$ compared to population smoking prevalence in US of $16.5 \%$ [11]. A cross-sectional analysis of 4103 laboratoryconfirmed COVID-19 patients treated at academic hospitals in New York City, demonstrated again a low smoking prevalence of 5.2\% [12]. A multivariate analysis performed by the New York researchers showed a significant protective effect against hospitalization among current and former tobacco users $(\mathrm{OR}=0.71,95 \%$ CI $0.57-0.87 p=0.001)$. Moreover, smoking was not a risk factor for critical disease or death. In Germany, a recent case series of hospitalized COVID-19 patients found a low smoking prevalence of about 6\% [13]. The protective association has been also recently observed in France where smoking prevalence reported for various age groups and levels of disease severity roughly average to about $1 / 5$ of the population prevalence [14]. These findings 
are consistent with the Chinese findings of Farsalinos et al. [9].

Given the circumstances of the pandemic, the quality of Chinese, US and German data is uncertain. The counterintuitive implications of these findings make it difficult to accept that somehow smoking could be a protective factor. Yet those who warn of increased risks for COVID-19 incidence and severity from smoking should not present this advice as anything but a supposition based on the known link between smoking and COVID-19 datasets.

For the evidence about the effects of smoking on COVID19, the accuracy of Chinese reporting could be questioned. Guan et al. [1] recently reported frequency of comorbidities in 1590 laboratory-confirmed hospitalized COVID-19 patients and added an additional 489 COVID-19 Chinese patients to the original sample of 1099 patients, altering the dataset that the authors had published a few weeks earlier [15]. A careful examination of both papers points to substantial discrepancies. The most inexplicable relates to the number of patients with chronic renal disease, with a phenomenal 34 -fold increase of cases from $8(0.7 \%$ of the total sample of 1099) to 269 (16.9\% of the total sample of 1590). The same discrepancy occurs with the number of COVID19 patients with cancer increasing 13 -fold from 0.9 to $8.2 \%$ and patients with immunodeficiency increasing 30 -fold from 0.2 to $3.7 \%$. Another puzzling discrepancy is that the larger study has fewer current/former smokers $(n=111)$ compared to numbers reported in the smaller study $(n=158)$. In a retrospective case-control Chinese study comparing hospitalized COVID-19 patients with ARDS to hospitalized H1N1 patients with ARDS, $11 \%$ of the 73 patients with ARDS due to SARS-CoV-2 were smokers and $47 \%$ of the 75 patients with ARDS due to H1N1 were smokers [16]. This substantial difference in the number of patients who smoke suggests that Chinese clinicians do not appear to be under-reporting patients' smoking status in their medical records. Moreover, one Chinese paper that actively gathered detailed smoking data rather than relying on medical records reported that only 2 of 140 COVID-19 patients smoked and that seven were former smokers [17]. Thus, similar low smoking prevalence among hospitalized COVID-19 patients was also found even when using better data collection methods for reporting smoking status. Of note, the Chinese paper which accurately reports smoking status observed the lowest smoking prevalence of all those included in the analysis by Farsalinos et al. ([9]; see Fig. 1).

Assuming limited confidence in the accuracy of the reporting of the studies from China, the US, and Germany, what are the implications of the findings? Given the magnitude of the protective effect, should people consider smoking until the pandemic subsides? Of course, such a highly provocative proposition is medically indefensible. Yet in the quest for new therapies to stem the spread of the Coronavirus pandemic and limit morbidity and mortality from COVID19 these findings deserve serious scientific consideration.

The frantic search for new therapies and vaccines to stem the spread of the Coronavirus pandemic and limit morbidity and mortality from COVID-19 drives the ultimate 21st century gold rush, to which new protagonists are continuously added on a weekly basis. As of the 23rd of April 2020, ClinicalTrials.gov listed a massive 801 ongoing clinical studies on COVID-19, including randomized trials investigating antivirals, biologics, immunomodulatory drugs, monoclonal antibodies, antibiotics, anti-inflammatory drugs, anticoagulants, and many others (https://clinicaltrials.gov/ct2/resul ts ? cond $=$ COVID \& term $=\&$ cntry $=\&$ state $=\&$ city $=\&$ dist $=$ ).

The analysis by Farsalinos et al. [9] may have therapeutic implications. Cigarette smoke is a complex mixture of thousands of harmful and potentially harmful constituents. Although the health risks of cigarette smoking are well documented, experimental evidence indicates that cigarette smoking may exert both adverse and beneficial effects of cigarette smoke to modulate the immune system [18]. Amongst the many constituents of cigarette smoke, carbon monoxide [19], several flavorings (e.g., menthol) [20], and nicotine [21] have been shown to exert anti-inflammatory and positive immune-modulatory function.

Based on the research that shows nicotine can prevent acute lung injury which is similar to COVID-19 pneumonia, and that nicotine inhibits the production of pro-inflammatory cytokines, the review authors hypothesize that nicotine might reduce the risk for severe COVID-19. In light of these findings, they propose that pharmaceutical nicotine may be used as a potential treatment option in COVID-19. There is concern about this potential therapy because the impact of long term use of nicotine replacement therapy on the immune system is not known. Yet nicotine is relatively safe for human consumption at low concentrations as nicotine replacement therapy as well as nicotine-containing vaping and heated tobacco products and has been used for relatively short periods of time in non-smokers [22-24]. In addition, the World Health Organization (WHO) lists nicotine replacement as an essential medicine. Therefore, health and regulatory authorities have sufficient evidence of clinical safety these medicines to fast-track clinical trials of nicotine patches.

Further evidence of the effect of nicotine on COVID-19 should be observed in Sweden where snus-an oral tobacco product that releases high concentrations of nicotine-consumption is highly prevalent. If the hypothesis of nicotine being protective against hospitalized COVID-19 is correct, this should be evident by analyzing the prevalence of snus usage in Swedish patients hospitalized with COVID-19. In the same way, the impact of other popular nicotine delivery products such as e-cigarettes and heated tobacco products on the severity of COVID-19 hospitalizations should be 
included in COVID-19 surveillance particularly in countries such as the UK where nicotine vaping is highly prevalent. The consistent observation that smoking prevalence is surprisingly low among hospitalized COVID-19 patients, should not be dismissed out of hand but monitored. The use of nicotine patches as a treatment for COVID-19 appears to have some potential in the race to find solutions for this terrible pandemic.

Given the importance of the active role that internists, general physicians and hospital staff play in assisting patients with COVID-19 and for patients with smoking-related diseases, Internal and Emergency Medicine remains committed to further advancing the scientific debate on COVID-19, including addressing the impact of smoking and vaping on COVID-19 disease.

\section{Compliance with ethical standards}

Conflict of interest RP is full-time employee at the University of Catania, Italy. In relation to the topic of communicable disease, RP has received research funding from Alfa-Wassermann, manufacturer of broad spectrum antibiotics. RP is also founder of the Center of Excellence for the acceleration of Harm Reduction at the University of Catania (CoEHAR), which has received a grant from Foundation for a Smoke Free World to develop and carry out 8 research projects and scientific advisor for LIAF, Lega Italiana Anti Fumo (Italian acronym for Italian Anti-Smoking League). GC has no conflict of interest.

Statement of human and animal rights This article does not contain any studies with human or animal subjects performed by any of the authors.

Informed consent Informed consent was not required for this type of study.

\section{References}

1. Guan WJ, Liang WH, Zhao Y, Liang HR, Chen ZS, China Medical Treatment Expert Group for Covid-19 et al (2020) Comorbidity and its impact on 1590 patients with Covid-19 in China: a nationwide analysis. Eur Respir J. https://doi.org/10.1183/13993003.00547 -2020 (Epub ahead of print)

2. Zhou F, Yu T, Du R, Fan G, Liu Y, Liu Z, Xiang J, Wang Y, Song B, Gu X, Guan L, Wei Y, Li H, Wu X, Xu J, Tu S, Zhang Y, Chen H, Cao B (2020) Clinical course and risk factors for mortality of adult inpatients with COVID-19 in Wuhan, China: a retrospective cohort study. Lancet 395(10229):1054-1062. https://doi. org/10.1016/S0140-6736(20)30566-3(Epub 2020 Mar 11. Erratum in: Lancet. 2020 Mar 28;395(10229):1038. Lancet. 2020 Mar 28;395(10229):1038)

3. Zhao X, Zhang B, Li P et al (2020) Incidence, clinical characteristics and prognostic factor of patients with COVID-19: a systematic review and meta-analysis. medRxiv. https://doi. org/10.1101/2020.03.17.20037572

4. Tan L, Wang Q, Zhang D, Ding J, Huang Q, Tang YQ, Wang Q, Miao H (2020) Lymphopenia predicts disease severity of COVID19: a descriptive and predictive study. Signal Transduct Target Ther 27(5):33. https://doi.org/10.1038/s41392-020-0148-4
5. Rodríguez LA, Ruigómez A, Wallander MA, Johansson S (2009) Acid-suppressive drugs and community-acquired pneumonia. Epidemiology 20:800-806. https://doi.org/10.1097/EDE.0b013e3181 b5f27d

6. Almirall J, Blanquer J, Bello S (2014) Community-acquired pneumonia among smokers. Arch Bronconeumol 50:250-254. https:// doi.org/10.1016/j.arbres.2013.11.016

7. Feldman C, Anderson R (2013) Cigarette smoking and mechanisms of susceptibility to infections of the respiratory tract and other organ systems. J Infect 67(3):169-184

8. Cai H (2020) Sex difference and smoking predisposition in patients with COVID-19. Lancet Respir Med. 8(4):e20. https://doi, org/10.1016/S2213-2600(20)30117-X(Epub 2020 Mar 11. Erratum in: Lancet Respir Med. 2020 Apr;8(4):e26)

9. Farsalinos KF, Barbouni A, Niaura R (2020) Systematic review of the prevalence of current smoking among hospitalized COVID-19 patients in China: could nicotine be a therapeutic option? Intern Emerg Med. https://doi.org/10.1007/s11739-020-02355-7

10. Chow N, Fleming-Dutra K, Gierke R, Hall A (2020) Preliminary estimates of the prevalence of selected underlying health conditions among patients with coronavirus disease 2019-United States, February 12-March 28, 2020. MMWR Morb Mortal Wkly Rep 69:382-386. https://doi.org/10.15585/mmwr.mm6913e2

11. Creamer MR, Wang TW, Babb S et al (2019) tobacco product use and cessation indicators among adults-United States, 2018. MMWR Morb Mortal Wkly Rep 68:1013-1019. https://doi. org/10.15585/mmwr.mm6845a2

12. Petrilli CM, Jones SA, Yang J, Rajagopalan H, O'Donnell LF, Chernyak Y, Tobin K, Cerfolio RJ, Francois F, Horwitz LI (2020) Factors associated with hospitalization and critical illness among 4,103 patients with Covid-19 disease in New York City. medRxiv. https://doi.org/10.1101/2020.04.08.20057794

13. https://www.medrxiv.org/content/10.1101/2020.04.08.20057794v1. Accessed 23 Apr 2020

14. Dreher M, Kersten A, Bickenbach J, Balfanz P, Hartmann B, Cornelissen C, Daher A, Stöhr R, Kleines M, Lemmen SW, Brokmann JC, Müller T, Müller-Wieland D, Marx G, Marx N (2020) Charakteristik von 50 hospitalisierten COVID-19-patienten mit und ohne ARDS. Dtsch Arztebl Int 117:271-278. https://doi.org/10.3238/arzte bl.2020.0271

15. Miyara M, Tubach F, Pourcher V et al. Low incidence of daily active tobacco smoking in patients with symptomatic COVID-19. https:// www.qeios.com/read/article/569. Accessed 23 Apr 2020

16. Guan WJ, Ni ZY, Hu Y, Liang WH, Ou CQ, He JX, Liu L, Shan H, Lei CL, Hui DSC, Du B, Li LJ, Zeng G, Yuen KY, Chen RC, Tang CL, Wang T, Chen PY, Xiang J, Li SY, Wang JL, Liang ZJ, Peng YX, Wei L, Liu Y, Hu YH, Peng P, Wang JM, Liu JY, Chen Z, Li G, Zheng ZJ, Qiu SQ, Luo J, Ye CJ, Zhu SY, Zhong NS (2020) Clinical Characteristics of Coronavirus Disease 2019 in China. N Engl J Med. https://doi.org/10.1056/NEJMoa2002032(Epub ahead of print)

17. Tang X, Du R, Wang R, Cao T, Guan L, Yang C, Zhu Q, Hu M, Li X, Li Y, Liang L, Tong Z, Sun B, Peng P, Shi H (2020) Comparison of hospitalized patients with ARDS caused by COVID-19 and H1N1. Chest. https://doi.org/10.1016/j.chest.2020.03.032(Epub ahead of print)

18. Zhang JJ, Dong X, Cao YY, Yuan YD, Yang YB, Yan YQ, Akdis CA, Gao YD (2020) Clinical characteristics of 140 patients infected with SARS-CoV-2 in Wuhan. China Allergy. https://doi. org/10.1111/all.14238

19. Sopori M (2002) Effects of cigarette smoke on the immune system. Nat Rev Immunol 2(5):372-377

20. Fagone P, Mazzon E, Bramanti P, Bendtzen K, Nicoletti F (2018) Gasotransmitters and the immune system: mode of action and novel therapeutic targets. Eur J Pharmacol 5(834):92-102. https://doi. org/10.1016/j.ejphar.2018.07.026 
21. Bastaki SM, Adeghate E, Amir N, Ojha S, Oz M (2018) Menthol inhibits oxidative stress and inflammation in acetic acid-induced colitis in rat colonic mucosa. Am J Transl Res 10(12):4210-4222

22. Hajiasgharzadeh K, Sadigh-Eteghad S, Mansoori B, Mokhtarzadeh A, Shanehbandi D, Doustvandi MA, Asadzadeh Z, Baradaran B (2019) Alpha7 nicotinic acetylcholine receptors in lung inflammation and carcinogenesis: friends or foes? J Cell Physiol. https://doi. org/10.1002/jcp. 28220

23. Greenland S, Satterfield M, Lanes S (1998) A meta-analysis to assess the incidence of adverse effects associated with the transdermal nicotine patch. Drug Saf 18:297-308

24. McNeill A, Brose LS, Calder R, Bauld L, Robson D (2020) Vaping in England: an evidence update including mental health and pregnancy, March 2020: a report commissioned by Public Health England. Public Health England, London

25. McNeill A, Brose LS, Calder R, Bauld L, Robson D (2018) Evidence review of e-cigarettes and heated tobacco products, 2018. A Report Commissioned by Public Health England. Public Health England, London

Publisher's Note Springer Nature remains neutral with regard to jurisdictional claims in published maps and institutional affiliations. 